\title{
COVID-19 and Asian American Pacific Islanders
}

\author{
Jiun-Ruey Hu, MD, $M P H^{7} \odot$, Margaret Wang, $M D^{2}$, and Francis $L u, M D^{3}$
}

'Department of Medicine, Vanderbilt University Medical Center, Nashville, TN, USA; ${ }^{2}$ Department of Psychiatry, University of Texas Southwestern Medical Center, Dallas, TX, USA; ${ }^{3}$ Department of Psychiatry, University of California Davis, Sacramento, CA, USA.

J Gen Intern Med 35(9):2763-4

DOI: $10.1007 / \mathrm{s} 11606-020-05953-5$

(c) Society of General Internal Medicine 2020

$\mathrm{T}$ he ongoing coronavirus disease 2019 (COVID-19) pandemic and tragic loss of life and employment have upended daily life in every community around the country. Unfortunately, Asian American Pacific Islanders (AAPIs), including those of non-Chinese heritage, have additionally been subjected to COVID-19-related discrimination. On March 14th, two Burmese-American children and their father were stabbed in public by a man who "thought the family was Chinese and infecting people with the coronavirus." ${ }^{\prime}$ On March 19th, the Asian Pacific Policy and Planning Council (A3PCON), a coalition of AAPI community organizations, set up a public reporting center for COVID-related discrimination. Within the first month, A3PCON received 1497 reports of COVID-19-related discrimination, from verbal harassment and being spat/coughed on to physical assault and being barred from establishments, with reported incidents 2.3 times higher for women than for men. ${ }^{2}$ Racism can cause psychosocial trauma and maladaptive coping behaviors, and worsen physical health and health inequities. ${ }^{3}$ In this viewpoint, we discuss how providers can help address AAPI racism within the physician-patient relationship - especially as general internists comprise a key position in the frontline against the pandemic.

At baseline, AAPIs have the lowest utilization of mental health services due to barriers in language, insurance, and cultural understanding. ${ }^{4}$ AAPI patients may not volunteer information to their doctors, and many avoid going out, even for essential needs, due to fear of violence and marginalization in public. In the primary care setting, clinicians can begin to address these issues by taking a moment to ask "Have you experienced any 'acts of discrimination' with everything going on?" Asking about discrimination in itself is an act of care, as it demonstrates acknowledgment of the

Jiun-Ruey Hu and Margaret Wang contributted equally to this work and are co-first authors.

Received May 1, 2020

Accepted May 29, 2020

Published online June 12, 2020 current challenges in these communities and helps establish trust. The American Psychiatric Association's DSM-5 Outline for Cultural Formulation notes that "Experiences of racism and discrimination in the larger society may impede establishing trust and safety in the clinical diagnostic encounter. Effects may include problems eliciting symptoms, misunderstanding of the cultural and clinical significance of symptoms and behaviors, and difficulty establishing or maintaining the rapport needed for an effective clinical alliance." Therefore, the Outline calls for the clinician to assess the cultural identity of the individual, cultural conceptualizations of distress, psychosocial stressors, and cultural features of vulnerability and resilience, and cultural features of the relationship between the individual and the clinician. ${ }^{5}$

To obtain this information, the general practitioner can use some of the 16 questions in the DSM-5 Cultural Formulation Interview. ${ }^{5}$ Assess cultural identity by asking, "For you, what are the most important aspects of your background or identity?" Assess conceptualizations of distress: "What brings you here today?" and "Why do you think this is happening to you? What are the causes of your problem?" Similarly, assess psychosocial stressors and cultural features of vulnerability and resilience: "Are there any kinds of support that make your problem better, such as support from family, friends, or others?" Determine cultural features of the relationship between the individual and the clinician: "Have you been concerned about doctors and patients coming from different backgrounds and is there anything that we can do to provide you with the care you need?" The patient is our greatest teacher on their experience.

Meanwhile, clinicians may find themselves as a witness observing a COVID-19-related discriminatory act against a colleague or a patient. The Confronting Prejudiced Response (CPR) Model formulates that, in overcoming obstacles to intervening as a bystander, one must recognize the prejudice, perceive it as an emergency, feel a sense of responsibility, and view the benefits as outweighing the costs. ${ }^{6}$ Although no validated intervention for COVID-19-related discrimination exists yet, bystanders may be empowered by current frameworks for bystander intervention, such as from the 4 Ds of Bystander Intervention (Distract, Delegate, Direct, Delay) adapted by the American Friends Service Committee to combat racism, to the Interrupt, Question, Acknowledge, Educate, 
Echo framework adapted from the Southern Poverty Law Center to promote tolerance in teaching. ${ }^{7}$

Consider the statement "Get me a different nurse who does not eat bats. I don't want to get 'Kung Flu'" using the latter framework. In nonviolent environments where teaching is possible, Interrupt: Call attention to the fact that an aggression occurred and did not go unnoticed. "Let's stop and talk about Asians eating bats giving you 'Kung Flu'." Question: Ask them to explain why the joke is funny and seek to understand their intentions. "What made you say that?" or "Why do you think that?" Acknowledge: Validate where possible, but set limits. "I understand that you are anxious about catching the virus yourself. However, I do not feel comfortable when you use a term like that." Educate: Bridge gaps by appealing to evidence. "The virus can infect folks of any race, so we all have to do our part." Echo: In group settings, if someone else has interrupted the bias, re-iterate the message and/or thank the first person for speaking up.

While there has been an increase in the use of hashtags that encourage violence against Chinese people, there has also been a spike in anti-Semitic hashtags espousing racist tropes about the virus "being used to kill off large portions of the population." ${ }^{8}$ As a medical community, we must make it clear to society that the racist rhetoric of blame threatens mental health and even lives - as we have already seen with the stabbing of the Burmese-American family. The scapegoating of minority populations to explain a pandemic should never be acceptable. Racism is a determinant of health and should not be overlooked by clinicians. The murders of George Floyd and Breonna Taylor last month are just two reminders of how systemic racism is a national public health crisis. Now and when the pandemic abates, we must work to ensure that medicine as a field continues to care for all minority communities.

Acknowledgments: We thank Dr. Nolan Kagetsu (Mount Sinai), Dr. Lia Thomas (UT Southwestern), Dr. Adam Brenner (UT Southwestern), and Dr. Esther Choo (Oregon Health and Science University) for their review of the manuscript.
Corresponding Author: Francis Lu, MD; Department of Psychiatry, University of California Davis, Sacramento, CA, USA (e-mail: francislumd@gmail.com).

Funding Information Dr. Wang was supported by R25MH101078 (Trivedi, $M H-P I)$.

\section{Compliance with Ethical Standards:}

Conflict of Interest: The authors declare that they do not have a conflict of interest.

\section{REFERENCES}

1. Ramirez M. FBI says Texas stabbing that targeted Asian-American family was hate crime fueled by coronavirus fears. The Dallas Morning News. https://www.dallasnews.com/news/crime/2020/04/01/fbi-says-texasstabbing-that-targeted-asian-american-family-was-hate-crime-fueled-bycoronavirus-fears/. Published April 1, 2020. Accessed April 19, 2020.

2. Jeung R. Incidents of Coronavirus Discrimination (April 232020 Report). Asian Pacific Policy and Planning Council. http://www. asianpacificpolicyandplanningcouncil.org/wp-content/uploads/A3PCON_ Public_Weekly_Report_3.pdf. Published March 25, 2020. Accessed April $11,2020$.

3. Bailey ZD, Krieger N, Agénor M, Graves J, Linos N, Bassett MT. Structural racism and health inequities in the USA: evidence and interventions. The Lancet. 2017;389(10077):1453-1463. doi:https://doi. org/10.1016/S0140-6736(17)30569-X

4. Lu FG. The poor mental health care of Asian Americans. West J Med. 2002; 176(4):224.

5. American Psychiatric Association. Diagnostic and Statistical Manual of Mental Disorders, Fifth Edition. Arlington, VA.: American Psychiatric Association, p. 749-754, 2013

6. Ashburn-Nardo L, Morris KA, Goodwin SA. The Confronting Prejudiced Responses (CPR) model: applying CPR in organizations. Academy of Management Learning \& Education. 2008;7(3):332-342.

7. Teaching Tolerance. How to Respond to Coronavirus Racism. Teaching Tolerance. https://www.tolerance.org/magazine/how-to-respond-to-coronavirus-racism. Published March 20, 2020. Accessed April 12, 2020.

8. Manavis S. Covid-19 has caused a major spike in anti-Chinese and antiSemitic hate speech. New Statesman. https://www.newstatesman.com/ science-tech/social-media/2020/04/covid-19-coronavirus-anti-chineseantisemitic-hate-speech-5g-conspiracy-theory. Published April 29, 2020. Accessed April 30, 2020.

Publisher's Note: Springer Nature remains neutral with regard to jurisdictional claims in published maps and institutional affiliations. 